\title{
The Effect of Stirring Time and Cast Thickness on Morphology, Permeability, and Thermal Stability of Polysulfone/Polyvinylidene Fluoride Blended Membranes
}

\author{
Pirim Setiarso ${ }^{1}$, Nita Kusumawati ${ }^{2}$, Maria Monica \\ Sianita $^{4}$, Ruwanti Dewi Cahya Ningrum ${ }^{5}$ \\ Department of Chemistry \\ Universitas Negeri Surabaya \\ Surabaya, Indonesia \\ 1'pirimsetiarso@unesa.ac.id, ${ }^{2}$ nkusumawati82@yahoo.com, \\ ${ }^{4}$ mariamonica@unesa.ac.id, ${ }^{5}$ ruwantidcn95@yahoo.com
}

\author{
Supari Muslim ${ }^{3}$ \\ ${ }^{3}$ Department of Electrical Engineering \\ Universitas Negeri Surabaya \\ Surabaya, Indonesia \\ ${ }^{3}$ suparimuslim@gmail.com
}

\begin{abstract}
Polysulfone/Polyvinylidene fluoride blend (PSf/PVDF) membranes with composition PSf/PVDF/NMP/NH4Cl (wt.\%) of $8 / 6 / 84 / 2$ supported on gauze fabric were successfully synthesized by a phase inversion method and immersion precipitation technique. Variations of stirring time and cast thickness were used to obtain an asymmetric structure with the least number of macrovoids. Increased stirring time of the casting solution and decreased cast thickness had an effect on the formation of a two layer, asymmetric structure resulted in higher porosity and lower thickness of the porous layer. Not only did it have an effect on the mechanical strength and permeability, the variations of stirring time and cast thickness had an influence on the thermal stability up to $470{ }^{\circ} \mathrm{C}$, the degradation temperature of the PSf.
\end{abstract}

Keywords - blending; membranes; polysulfone; polyvinylidene fluoride; pure water permeability

\section{INTRODUCTION}

Polysulfone (PSf) is a polymer that has been widely used in the manufacture of micro-ultrafiltration membranes [1-2]. The symmetric structure of the pores, with a thick porous layer in the cross-section structure beneath the skin, led to the high mechanical strength of the PSf membranes [1-6]. However, the symmetric structure of the PSf membrane also brought negative impacts in the form of a limited range of pore sizes. A uniform large pore size and relatively few pores in the PSf membranes led to a low level of porosity. The existence of the symmetric structure, as well as the limited range of pore size and porosity, caused a high fouling potential and low utilization periods for the PSf membranes [7-9]. This has limited the use of the membranes in industry. In addition to the above features of the currently commercially available PSf membranes, a potential membrane material must have a high thermal stability, chemical resistance to the corrosion caused by acids, bases, and bacteria, and it must also have an asymmetric structure formation, as well as good mechanical strength and performance [10-13].
Some of the methods that can be used to improve the characteristics and performance of the PSf membranes include physical blending [14-15], chemical grafting [16-17], and modifying the surface $[4,7,18-20]$. Among the three methods, the polymer blending is of great interest because it is the most versatile way of achieving materials with new desirable properties [21], it is less complicated than developing a new polymerization process, the least expensive, convenient in operation and uses mild conditions [22]. We have previously reported an effort to improve the characteristics and performance of PSf membranes through physical blending using polyvinylidene fluoride (PVDF) and a gauze fabric as a supporting layer [23]. The ability of PVDF to form an asymmetric structure as well as the advantages of thermal stability, chemical resistance to acids, bases, and oxidizing agents and high permeability in PVDF membranes [24] makes PVDF to be a good blending agent for PSf.

However, the high quantity of macrovoids formed in the cross-section structure of the PSf/PVDF membranes, as we reported in ref. [7], should get more attention. The macrovoid occurrence in the membranes causes high permeability as well as low mechanical strength and selectivity. One of the solutions that can be used to overcome these problems is to use casting conditions that are able to lead to the formation of more dense membranes [1-2]. The stirring process of the casting solution and the casting thickness of the membranes are two among the many factors that affect the final morphology of the membranes [1-2]. Based on the literature, this research studied the influence of stirring time and casting thickness on the structure and properties of PSf/PVDF membrane. 


\section{MATERIAL AND METHODS}

\section{A. Material}

Polysulfone (PSf) (d=1.24 g.mL $\mathrm{mL}^{-1}$ at $\left.25{ }^{\circ} \mathrm{C}, \mathrm{Mw} 35,000\right)$ and polyvinylidene fluoride (PVDF) (powder, Mw 354,000) were supplied by Sigma-Aldrich LTd., Singapore; they were used as the main polymer materials for the PSf/PVDF membranes. 1-Methyl-2-pyrrolidone (NMP) ( $\geq 99.7 \%$ ), also purchased from Sigma-Aldrich, was used as the PSf and PVDF polymers solvent. Ammonium chloride $\left(\mathrm{NH}_{4} \mathrm{Cl}\right)$ (powder, $\geq 99.5 \%$ ) was procured from Honeywell Riedel de Haen, Germany, and was used as the membrane pore forming additive, while the gauze fabric (254 mesh) was supplied by PT. Kasa Husada Wira Jatim, Indonesia and used as the membrane support fabric. Distilled water was used as the nonsolvent for the polymer precipitation. Sulfuric acid $\left(\mathrm{H}_{2} \mathrm{SO}_{4}\right)$ (>98\%) was purchased from Ajax Finechem, Australia) and sodium hydroxide $(\mathrm{NaOH})$ (pellet, $\geq 98 \%$ ) was procured from Sigma-Aldrich, Singapore; they were used in order to test the membranes chemical resistance [26].

\section{B. Instrumentation}

Surface and cross-section morphology of the PSf/PVDF membranes were observed using a scanning electron microscope (SEM) (ZEISS EVO MA 10, ZEISS International Ltd., Singapore). The membrane cross section was prepared by cryo-fracture at the temperature of liquid nitrogen. The membrane surface was coated with a thin layer of gold before imaging. The mechanical strength of the membranes was analyzed using a Strograph (RCT-10KN-AF, Toyo Seiki Seisaku-sho Ltd., Japan) as a tensile tester. The water permeation characterizations of the PSf/PVDF membranes were carried out by a dead-end membrane reactor (self-made) with distilled water as the feed solution. The thermal decomposition of the membranes was analyzed using differential scanning calorimetry-thermal gravimetric analysis (DSC-TGA) (STA-6000, Perkin Elmer, Inc., USA). Thermogravimetric analysis was carried out under $\mathrm{N}_{2}$ atmosphere, from 0 to $890{ }^{\circ} \mathrm{C}$ with a heating rate of $10{ }^{\circ} \mathrm{C}$ $\min ^{-1}[25]$.

\section{Preparation of PSf/PVDF Asymmetric Membrane}

The PSf/PVDF asymmetric dense membranes were prepared by phase inversion, induced by immersion precipitation; the following procedure was used. $8 \%$ (wt $\%$ ) PSf and 2\% (wt \%) $\mathrm{NH}_{4} \mathrm{Cl}$ were dissolved in $84 \%$ (wt $\%$ ) NMP. In order to get homogeneous casting solutions, the mixture was stirred using a magnetic stirrer at $60{ }^{\circ} \mathrm{C}$ with different stirring times of 105, 120, and 180 minutes. $6 \mathrm{wt} . \%$ PVDF was then added to the casting solution under continued stirring. To ensure the homogeneity of the PVDF in the PSf casting solution, stirring was continued for 30 minutes. The membranes were then cast using a casting knife with various casting thicknesses $0.3,0.7$ and $0.8 \mathrm{~mm}$, on a glass plate which had been overlaid with gauze, at a temperature of $80^{\circ} \mathrm{C}$. After 5 minutes the glass plate was immersed in water as a non-solvent and held until the membranes detached from the glass plates. The membranes were then washed with running water to remove the remains of the $\mathrm{NMP}$ and $\mathrm{NH}_{4} \mathrm{Cl}$ [26] and dried in the open air before use.

\section{PREPARE Your PAPER BEFORE STYLING}

\section{A. PSf/PVDF Asymmetric Membranes}

SEM images of the free surface and cross-section morphologies of the PSf/PVDF blended membrane with a cast thickness of $0.7 \mathrm{~mm}$ and prepared with the three stirring times are shown in Fig. 1; the cross-sections show the asymmetric structure that was formed in the membrane with the appearance of a higher porosity with increasing PSf casting solution stirring time. This indicates that the increased stirring time of the casting solution, which in this case was only applied to the PSf polymer, played a role in the formation of the more porous membrane in the cross-sections of the PSf/PVDF membranes. A longer stirring time resulted in optimum solubility of the PSf and $\mathrm{NH}_{4} \mathrm{Cl}$ in the NMP solvent and a more homogeneous mixture of $\mathrm{PSf}$ and $\mathrm{NH}_{4} \mathrm{Cl}$ molecules in the casting solution. The presence of homogeneous $\mathrm{NH}_{4} \mathrm{Cl}$ in the casting solution decreased the distance between the polymer molecules, both of PSf and the PVDF that was added later, which would induce the formation of 2 (two) areas within the membrane, i.e., polymer-rich and polymer-poor regions with smaller pore sizes. The polymersrich regions are called the membrane matrix, while the poorer areas are the membrane pores. An increased quantity of polymer-poor regions (porosity) occured as effect of an increase in $\mathrm{NH}_{4} \mathrm{Cl}$ homogenity in the membrane casting solution. The increase in PSf/PVDF membrane porosity led to an increase in membrane permeability to pure water.

In general, both symmetric and asymmetric membranes have a number of parts, which include: (a) the skin layer (solid, minimal pores); and (b) sub skin layer (porous part). The sub layer (porous layer) is divided into 2 parts, namely micropore and macrovoid. The SEM images of the crosssections of the PSf/PVDF membranes of various thicknesses (see Fig. 2) showed the emergence of the asymmetric structure with maximum macrovoids and highest skin layer thickness in the PSf/PVDF membrane porous layer with the greatest cast thickness. This suggests that the high density of particles in the casting solution, along with the decrease in the volume of casting solution as a result of the application of low casting thickness for the thin membranes, will induce the formation of smaller pore volumes. 


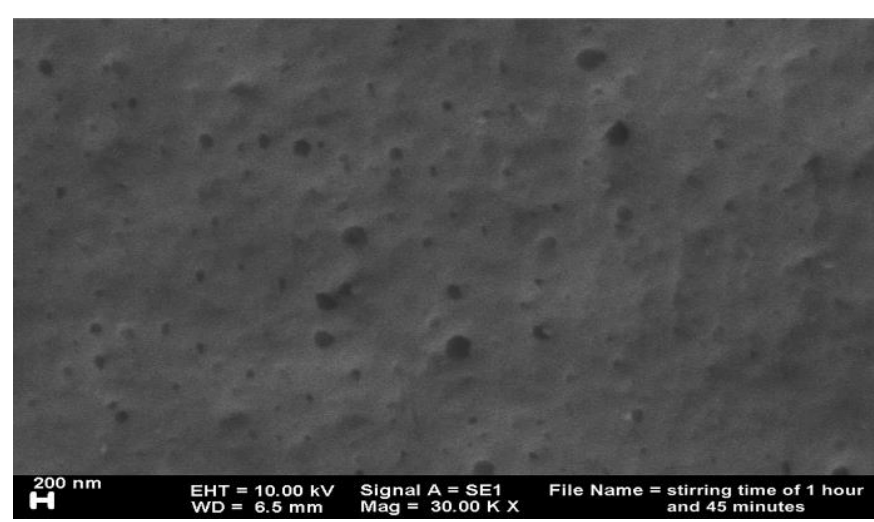

(a1)

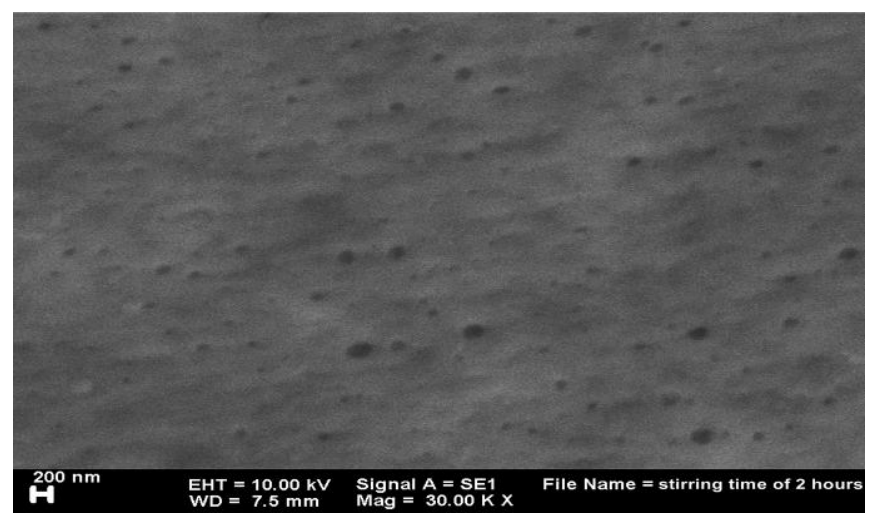

(b1)

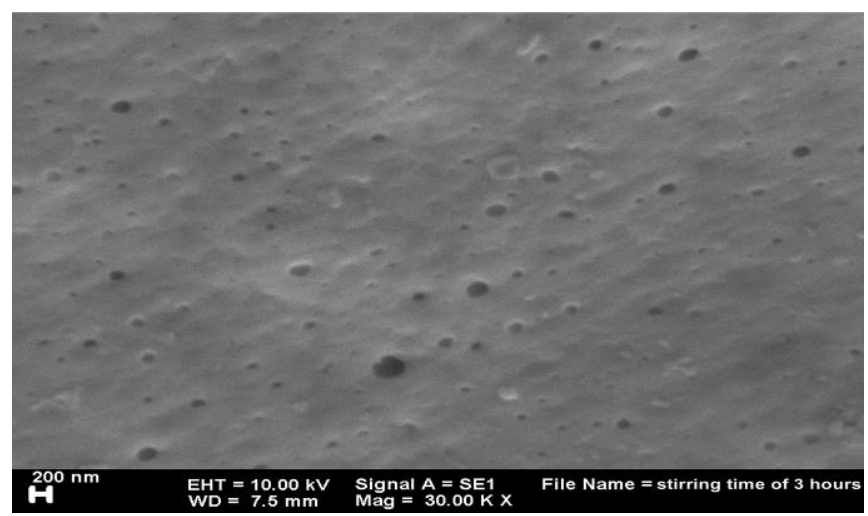

(c1)

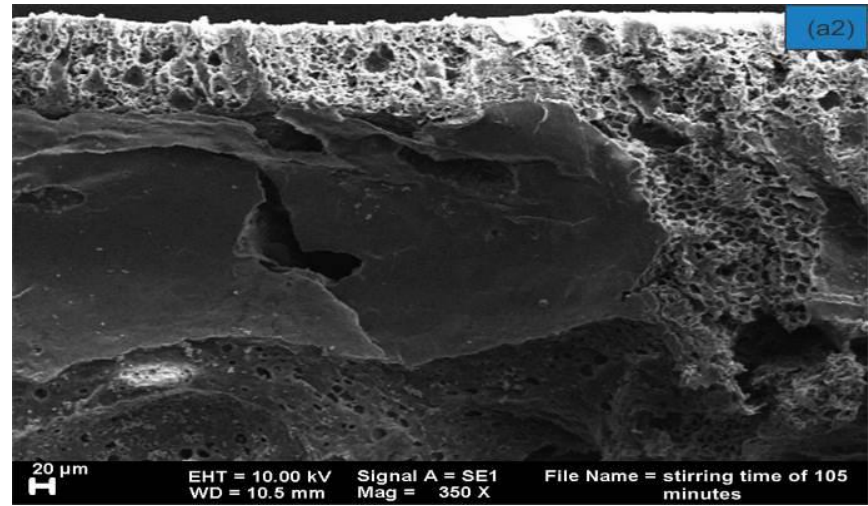

(a2)

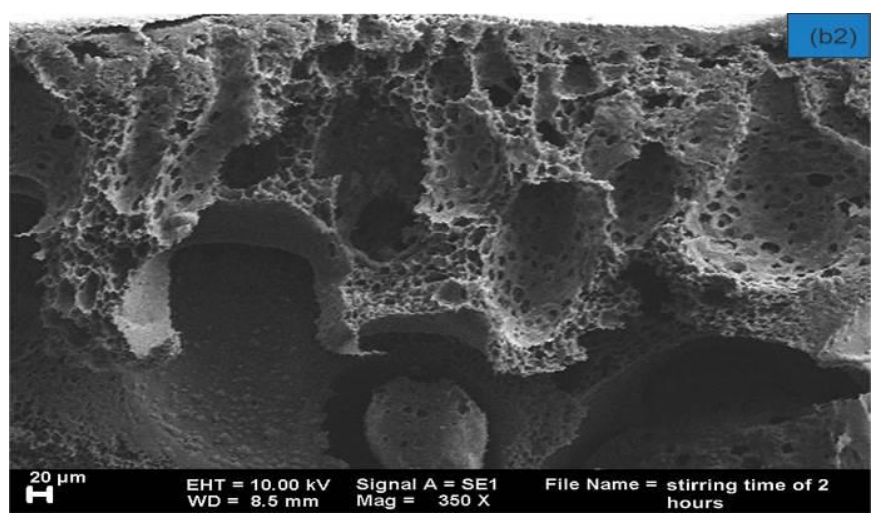

(b2)

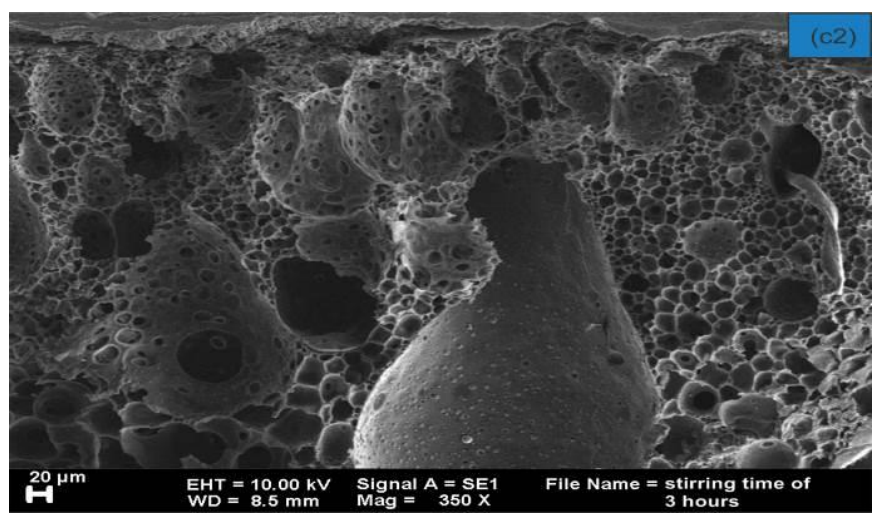

(c2)

Fig. 1. SEM images of the PSf/PVDF membrane surfaces with magnification $30.00 \mathrm{~K} x$ with various stirring times: (a1) 105 minute; (b1) 120 minute; and (c1) 180 minute: and cross-sections with magnification $350 \mathrm{x}$ : (a2) 105 minute; (b2) 120 minute; and (c2) 180 minute, all with cast thickness $0.8 \mathrm{~mm}$ 


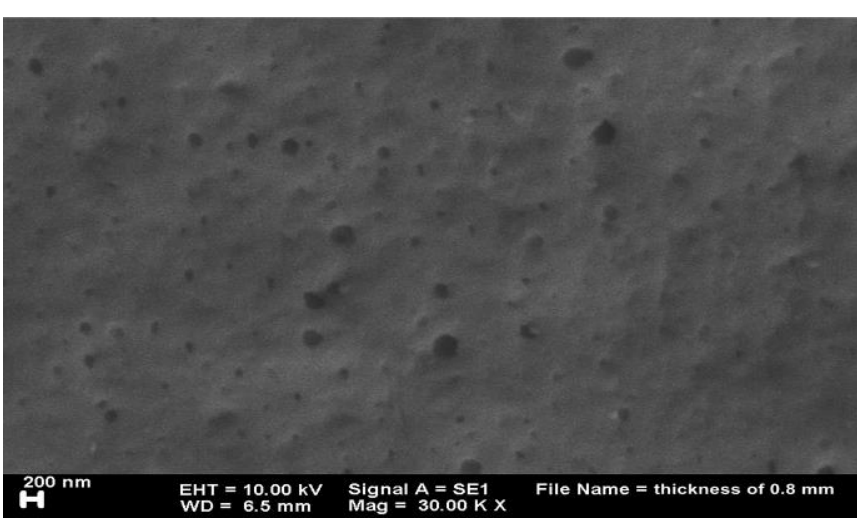

(d1)

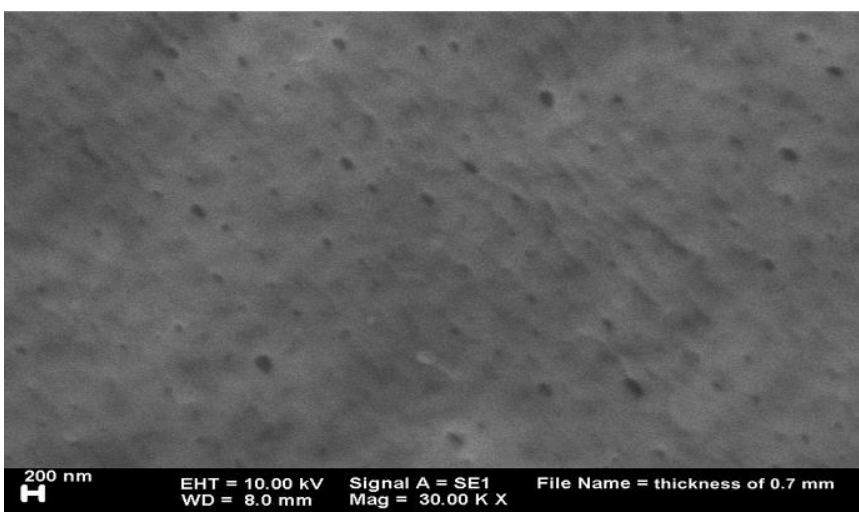

(e1)

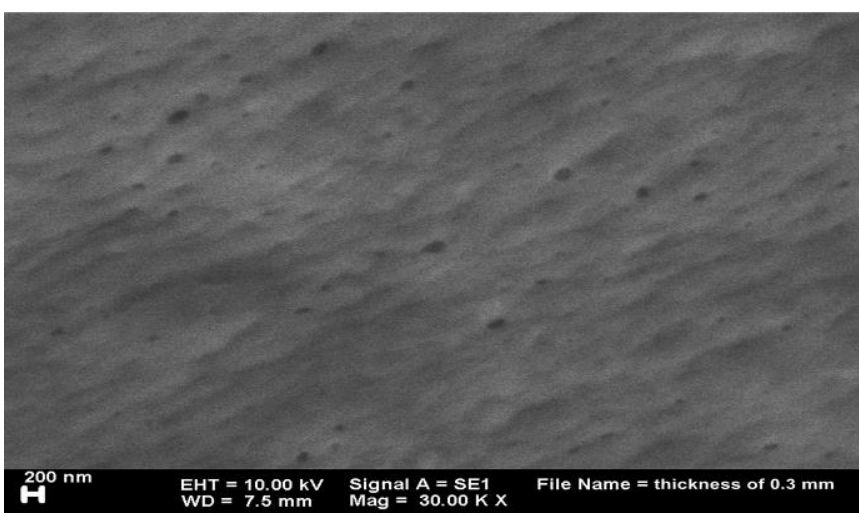

(f1)

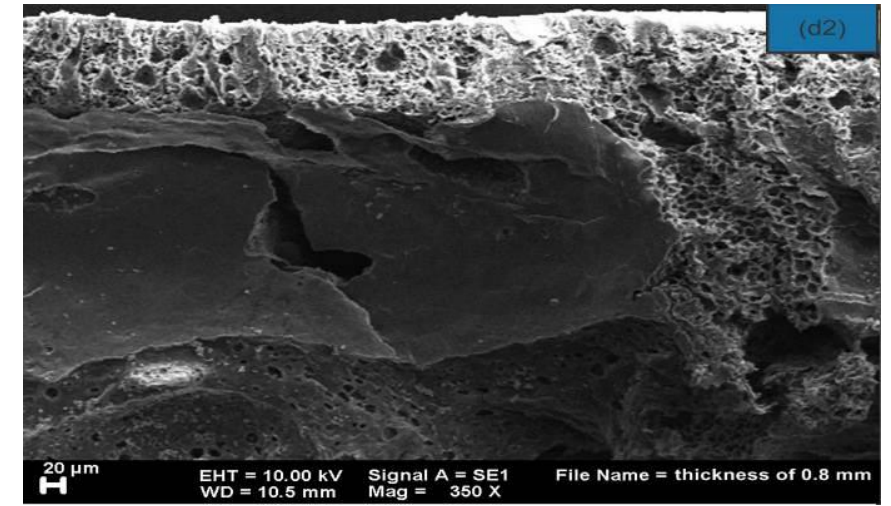

(d2)

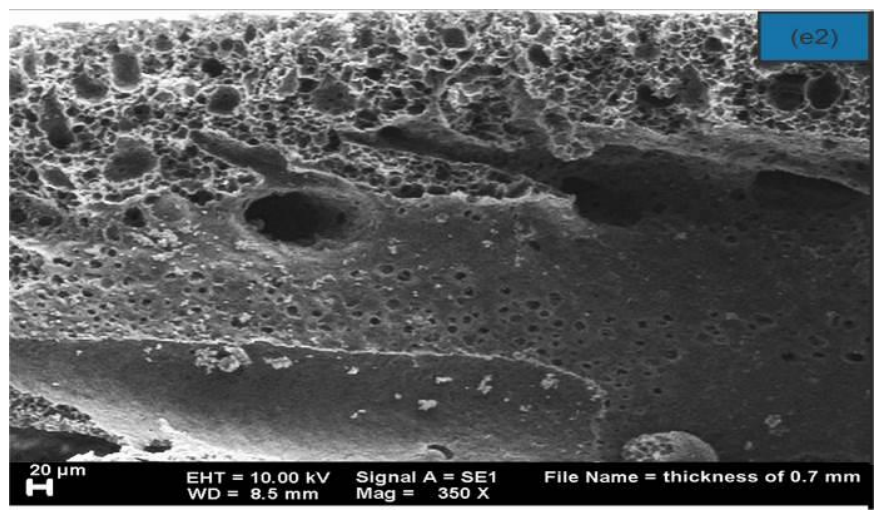

(e2)

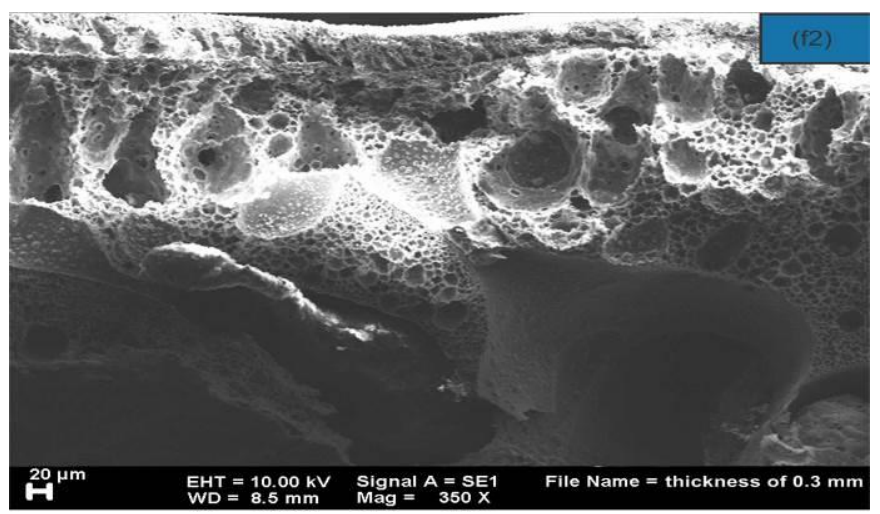

(f2)

Fig. 2. SEM images of the PSf/PVDF membrane surfaces with magnification $30.00 \mathrm{~K} x$ with cast thicknesses: (d1) $0.8 \mathrm{~mm}$; (e1) $0.7 \mathrm{~mm}$; and (f1) $0.3 \mathrm{~mm}$ and cross-sections with magnification $350 \mathrm{x}$ : (d2) $0.8 \mathrm{~mm}$; (e2) $0.7 \mathrm{~mm}$; and (f2) $0.3 \mathrm{~mm}$, all with 105 minutes stirring time

\section{B. Permeability Of The PSf/PVDF Asymmetric Membranes}

The pure water permeability test results for the PSf/PVDF asymmetric membrane using the dead-end membrane reactor showed the lowest permeability for PSf/PVDF membrane that was prepared with a cast thickness of $0.8 \mathrm{~mm}$ and stirring time of 105 minutes compared to membranes of the same thickness that were prepared with stirring times of 120 minutes and 180 minutes. The pure water permeability of the membrane that was prepared with a stirring time of 105 minutes was 32078
$\mathrm{Lm}^{-2} \mathrm{~h}^{-1}$, while for membranes that were prepared with stirring times of 120 minutes and 180 minutes were 35777 and $46075 \mathrm{Lm}^{-2} \mathrm{~h}^{-1}$, respectively. A longer stirring time of the PSf casting solution tended to increase the solubility of the PSf and $\mathrm{NH}_{4} \mathrm{Cl}$ particles in the solvent used. Thus, an increase in stirring time will automatically affect the homogeneity of the pore-forming particles $\left(\mathrm{NH}_{4} \mathrm{Cl}\right)$ in the casting solution so that the optimum number of interactions may occur between PSf, PVDF, and PSf-PVDF. However, in accordance with the permeability data of the PSf/PVDF membranes, the decrease of the membrane skin layer 
thickness as a result of the increase of the number of membrane polymer interactions is known to have a more significant effect on permeability than the decrease of pore size.

In addition, permeability tests were carried out on the PSf/PVDF membranes that were prepared with different cast thicknesses. The PSf/PVDF membrane that was prepared with a stirring time of 105 minutes and cast thickness of $0.3 \mathrm{~mm}$ had a permeability of $76556 \mathrm{Lm}^{-2} \mathrm{~h}^{-1}$, while the PSf/PVDF membrane which were prepared with stirring time of 105 minutes and cast thicknesses of 0.7 and $0.8 \mathrm{~mm}$ had water permeabilities of 56870 and $32078 \mathrm{Lm}^{-}$ ${ }^{2} \mathrm{~h}^{-1}$. The cross-section morphology of the PSf/PVDF blended membrane that was prepared with a cast thickness of $0.3 \mathrm{~mm}$ and $105 \mathrm{~min}$ stirring time showed the existence of the asymmetric structure with the lowest membrane skin layer thickness and a macrovoids structure in the porous layer of the membrane. This caused the membrane of this type to have the highest water permeability compared with PSf/PVDF blended membrane prepared with the same strirring time (105 minutes) but with higher cast thicknesses. These conditions indicated that a decrease in membrane thickness had a more significant effect on pure water permeability compared with decreased pore size and macrovoid volume reduction of the membrane induced by an increase in interaction density levels occuring between membrane constituent particles.

\section{Thermal Stability Of The PSf/PVDF Asymmetric Membranes}

Thermogravimetric analysis results showed that the PSf and PVDF decomposed in several steps, as shown in Figs. 3 and 4. The decomposition is indicated by the weight lose during the temperature increase. The first and second mass reductions, which were detected at around $100-160{ }^{\circ} \mathrm{C}$ and 220-350 ${ }^{\circ} \mathrm{C}$ correspond to the releasing of water vapor [26] and $300-340{ }^{\circ} \mathrm{C}$ to the releasing of NMP that was adsorbed on the surface and internal pore of PSf/PVDF membrane, respectively. The third mass reduction occurred at about 450-500 ${ }^{\circ} \mathrm{C}$. We suggest the third mass reduction was caused by the decomposition of the $28 \mathrm{wt} . \%$ PVDF in the films. The fourth mass reduction, at about $470-650{ }^{\circ} \mathrm{C}$, was caused by the decomposition of PSf. This result is comparable with that reported in Ref [26], in which PSf decomposed at $460{ }^{\circ} \mathrm{C}$.

However, based on the thermogram Fig. 3 and 4 it appears that the increased solubility of polymer and porogenic particles in NMP solvents occurring with increased stirring time will induce the formation of PSf/PVDF membranes with smaller pore size and decreased membrane thickness. The condition has induced decreased thermal resistance of the membrane. Meanwhile, the increasing of interaction density between membrane constituent particles along with the decrease of membrane casting thickness has no significant effect on the thermal resistance of PSf/PVDF membrane. The higher particle density levels along with the decrease in the casting thickness cause the decrease in thermal resistance that is not as significant as the result of increased stirring time.

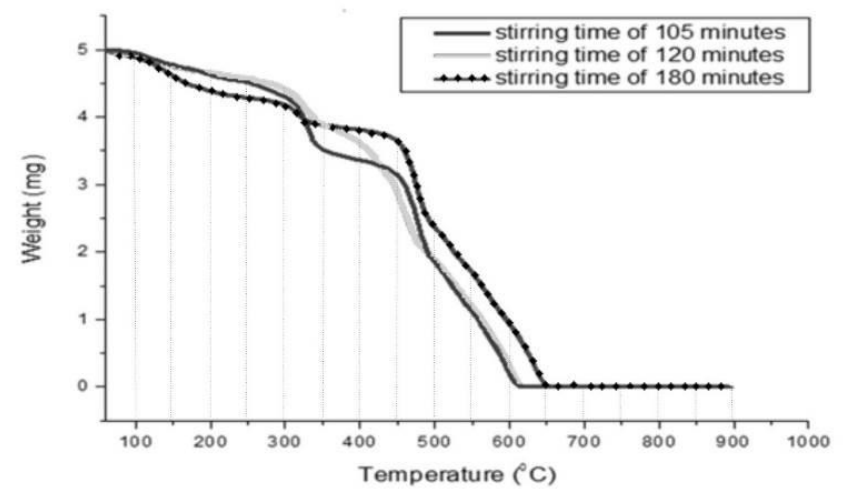

Fig. 3. TGA thermograms of the PSf/PVDF membranes with cast thickness of $0.8 \mathrm{~mm}$ and stirring times: (a) 105 minutes; (b) 120 minutes; (c) 180 minutes.

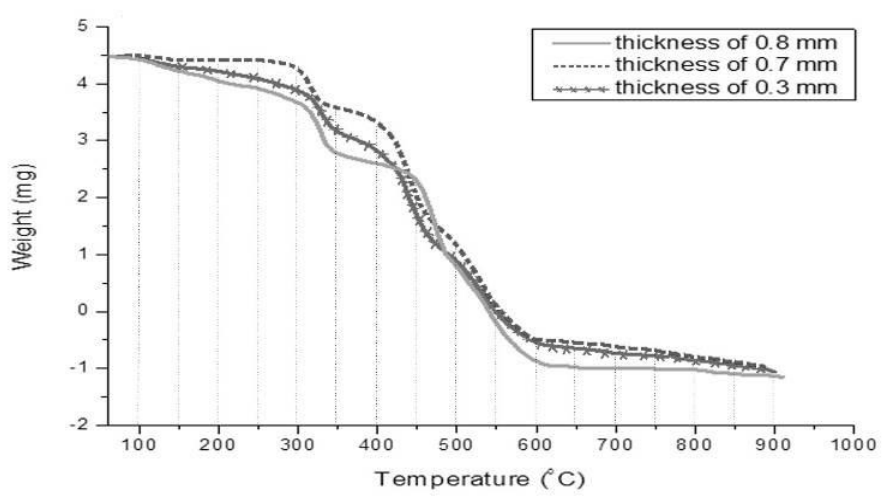

Fig. 4. TGA thermograms of the PSf/PVDF membranes with 105 minutes stirring time and cast thicknesses: (a) $0.8 \mathrm{~mm}$; (b) $0.7 \mathrm{~mm}$; (c) $0.3 \mathrm{~mm}$

\section{CONCLUSIONS}

The membrane morphology, as a result of different stirring time and casting thickness, showed some differences in porosity and membrane skin layer thickness; a longer stirring time resulted in higher porosity with lower pore size and lower skin layer thickness. Similar characteristics were also observed along with a decrease in membrane cast thickness. Mechanical strength and permeability test results showed that longer stirring time and lower cast thickness resulted in lower mechanical strength and higher pure water permeability. Thermogravimetric analysis results revealed differences in stirring time and casting thickness resulted in no significant changes in the thermal stability of the PSf/PVDF membrane.

Young's moduli values of the PSf/PVDF membranes prepared with stirring times of 105 minutes, 120 minutes and 180 minutes were $1465 ; 1043$ and $874 \mathrm{Nm}^{-2}$ while the water permeabilities were $32078 ; 35777$ and $46075 \mathrm{Lm}^{-2} \mathrm{~h}^{-1}$, respectively. In addition, Young's moduli values of the membranes prepared with cast thicknesses of $0.3 \mathrm{~mm}, 0.7$ $\mathrm{mm}$ and $0.8 \mathrm{~mm}$ and all with a stirring time of 105 minutes were 668; 1037 and $1465 \mathrm{Nm}^{-2}$ while the water permeabilities were $76556 ; 56870$ and $32078 \mathrm{Lm}^{-2} \mathrm{~h}^{-1}$, respectively. 


\section{ACKNOWLEDGMENT}

The authors acknowledge the financial support by Indonesian Ministry of Higher Education, Research and Technology.

\section{REFERENCES}

[1] I.C. Kim and K.H. Lee, "Effect of Various Additives on Pore Size of Polysulfone Membrane by Phase Inversion Process," J. Appl. Polym. Sci., 89(9), pp. 2562-2566, Augustus 2003.

[2] S. Hamzah, N. Ali, M.M. Ariffin, A. Ali, and A.W. Mohammad, "High Performance of Polysulfone Ultrafiltration Membrane: Effect of Polymer Concentration,” J. Eng. Appl. Sci., 9, pp. 2543, 2014.

[3] S.P. Nunes and K.V. Peinemann, Membrane Technology in Chemical Industry, Weinheim, Germany: WILEY-VCH Verlag GmbH \& Co. KGaA, 2006, pp. 23-25.

[4] H. Julian and I.G. Wenten, "Polysulfone Membranes for $\mathrm{CO}_{2} / \mathrm{CH}_{4}$ Separation: State of The Art," IOSR J. Eng., 2, pp. 484-495, 2012.

[5] S. Rafiq, Z. Mana, A. Maulud, N. Muhammad and S. Maitra, "Separation of $\mathrm{CO}_{2}$ from $\mathrm{CH}_{4}$ using Polysulfone/Polyimide Silica Nanocomposite Membranes," Sep. Purif. Tech., 90, pp. 162-172, 2012.

[6] S.M. Momeni and Pakizeh, "Preparation, Characterization and Gas Permeation Study of PSf/MgO Nanocomposite Membrane,” Braz. J. Chem. Eng., 30, pp. 589-597, 2013.

[7] N. Kusumawati, T. Koestiari, and M. Monica, "The Influence of Casting Solution Composition and Stirring Conditions Against Mechanical Strength and Performance of Polyvinylidene Fluoride (PVDF)-Polysulfone (PSf) Composite Membrane on Textile Industrial Wastewater Treatment," Res. J. Pharm. Biol. Chem. Sci., 6, pp. 272, 2015 .

[8] K.D.A. Maharani and N. Kusumawati, "The Effect of Casting Solution and Non Solvent Composition on The Performance of Polysulfone Membranes Against Chromium (VI)," Res. J. Pharm. Biol. Chem. Sci., 7, pp. 496, 2016

[9] N. Kusumawati, P. Setiarso, S. Muslim, N. Purwidiani, "Synergistic Ability of PSf and PVDF to Develop High-Performance PSf/PVDF Coated Membrane for Water Treatment," RASAYAN J. Chem., 11(1), pp. 260-279, 2018.

[10] T. Matsuura, Synthetic Membranes and Membrane Separation Process, Boca Raton, Florida: CRC Press Inc, 1994, pp. 11-12.

[11] N. Hilal, O.O. Ogunbiyi, N.J. Miles, and R. Nigmatullin, "Methods Employed for Control of Foulingin MF and UF Membranes: A Comprehensive Review," Sep. Sci. Technol., 40, pp. 1957, 2005.

[12] F. Shen, X. Lu, X. Bian, and L. Shi, "Preparation and Hydrophilicity Study of Poly(vinyl-butyral),” J. Membr. Sci., 265, pp. 74-84, 2005.
[13] P.L. Clech, V. Chen, and T.A.G Fane, "Fouling in Membrane Bioreactors Used in Wastewater Treatment", J. Membr. Sci., 284, pp. $17-53,2006$.

[14] M. Ulbricht, "Advanced functional polymer membranes," Polymer, 47, pp. 2217-2262, 2006

[15] F. Liu, N.A. Hashim, Y. Liu, M.R.M. Abed, and K. Li, "Progress in the Production and Modification of PVDF Membranes," J. Membr. Sci., 375, pp. 1-27, 2011

[16] J.F. Hester, P. Banerjee, Y.Y. Won, A. Akthakul, M.H. Acar, and A.M. Mayes, "ATRP of Amphiphilic Graft Copolymers Based on PVDF and Their Use as Membrane Additives," Macromolecules, 35, pp. 7652, 2002

[17] M. Pakizeh, S.A.A. Mansoori, M.P. Chenar, and M.N. Mahboub "Modification of PSf Membrane Nanostructure using Different Fabrication Parameters and Investigation of The $\mathrm{CO}_{2}$ Separation Properties of PDMS-Coated PSf Composite Membrane," Braz. J. Chem. Eng., 30, pp. 345-354, 2013

[18] D.R. Paul and S. Newman, S (Eds.), Polymer Blends, New York: Academic Press, 1978, pp. 30.

[19] R.W. Baker, Membrane Technology and Applications, Chichester: Wiley, 2004, pp. 1-3.

[20] S.H. Ye, J. Watanabe, Y. Iwasaki, and K. Ishihara, "In Situ Modification on Cellulose Acetate Hollow Fiber Membrane Modified with Phospholipid Polymer for Biomedical Application," J. Membr. Sci., 249, pp. 133, 2005.

[21] S.A.A. Mansoori, M. Pakizeh, and A. Jomekian, " $\mathrm{CO}_{2}$ and $\mathrm{H}_{2}$ Selectivity Properties of PDMS/PSf Membrane Prepared at Different Conditions," Front. Chem. Sci. Eng., 5, pp. 500-513, 2011.

[22] Y.N. Yang, H.X. Zhang, and P. Wang, "The Influence of Nano-Sized $\mathrm{TiO}_{2}$ Fillers on The Morphologies and Properties of PSf UF Membrane,” J. Membr. Sci., 288, pp. 231-238, 2007.

[23] S.I. Voicu, F. Aldea, M. Radut, and G. Nechifor, "Nanostructured Polysulfone Composite Membrane," U.P.B. Sci. Bull. Series B, 70, pp. 39-46, 2008.

[24] N. Kusumawati, A. Wijiastuti, and A.G. Santoso, "Manufacture of PVDF-Kitosan Composite Membrane and Its Utilization in Batik Industrial Wastewater Treatment," Res. J. Pharm. Biol. Chem. Sci., 5, pp. 496, 2015.

[25] E.P. Setyaningsih, M. Machfudzoh, W.P. Utomo, and H. Fansuri, "Preparation of $\mathrm{CiO}_{3}$ Asymmetric Membrane using Polyetherimide as Binder Polymer," Indones. J. Chem, 16, pp. 20-24, 2016.

[26] R.D.C Ningrum and N. Kusumawati, "Development and Characterization of Polysulfone/Polyvinylidene Fluoride Blend Membrane Induced by Delayed Liquid-Liquid Demixing," Int. J. Adv. Sci. Eng. Inform. Tech., 6, pp. 716-722, 2016. 